\title{
Corrigendum: Fluid responsiveness in the pediatric population
}

\author{
Ji-Hyun Lee, Eun-Hee Kim, Young-Eun Jang, Hee-Soo Kim, and \\ Jin-Tae Kim \\ Department of Anesthesiology and Pain Medicine, Seoul National University Hospital, Seoul National University \\ College of Medicine, Seoul, Korea
}

\section{Korean J Anesthesiol 2019 October 72(5): 429-440}

\section{https://doi.org/10.4097/kja.19305}

The article by Lee et al. entitled, "Fluid responsiveness in the pediatric population" (Korean J Anesthesiol 2019 Oct; 72(5): 429-440) contained an error in Fig. 2.

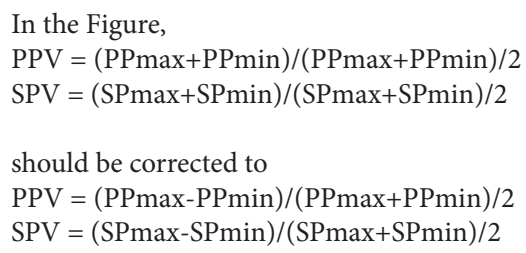

The authors sincerely apologize for this error and the revised figure is shown below.

Arterial wave
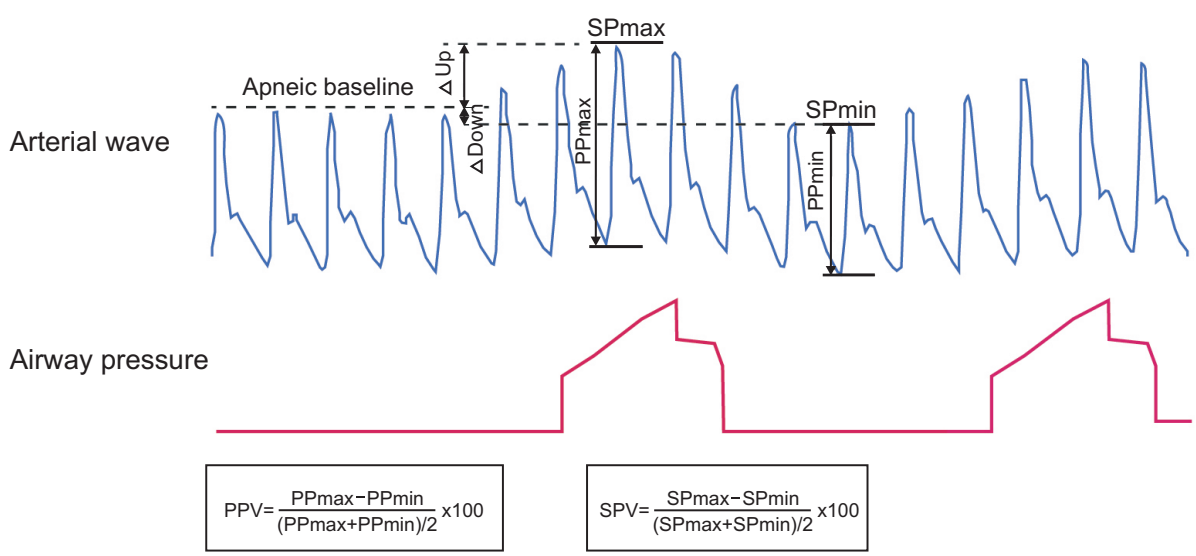

Korean J Anesthesiol 2019 December 72(6): 624

https://doi.org/10.4097/kja.19305.c1

() This is an open-access article distributed under the terms of the Creative Commons Attribution Non-Commercial License (http://creativecommons.org/ licenses/by-nc/4.0/), which permits unrestricted non-commercial use, distribution, and reproduction in any medium, provided the original work is properly cited. 